Utah State University

DigitalCommons@USU

\title{
Observations on the ecology and evolution of quaking aspen, Populus tremuloides, in the Colorado Front Range
}

Jeffry B. Mitton

Michael C. Grant

Follow this and additional works at: https://digitalcommons.usu.edu/aspen_bib

Part of the Forest Sciences Commons

\section{Recommended Citation}

Mitton, Jeffry B. and Grant, Michael C., "Observations on the ecology and evolution of quaking aspen, Populus tremuloides, in the Colorado Front Range" (1980). Aspen Bibliography. Paper 4540.

https://digitalcommons.usu.edu/aspen_bib/4540

This Article is brought to you for free and open access by the Aspen Research at DigitalCommons@USU. It has been accepted for inclusion in Aspen Bibliography by an authorized administrator of DigitalCommons@USU. For more information, please contact

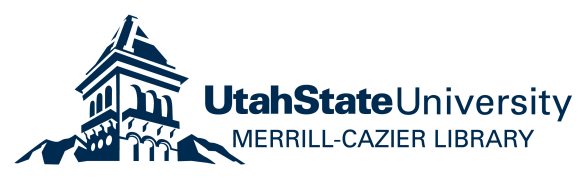


Amer. J. Bot. 67(2): 202-209.

\title{
JefFry B. Mitton and Michael C. Grant \\ Department of Environmental. Population, and Organismic Biology: and Institute of Arctic and Alpine Research. University of Colorado. Boulder, Colorado $\$ 0309$
}

\section{A B S T R A C T}

\begin{abstract}
Three protein polymorphisms and annual width increments measured from cores were used to study the ecology and evolution of quakin̈g aspen. Populus tremuloides Michx.. in the Front Range of Colorado. Correlations among elevation, age and diameter of the largest standing ramet, and sex and mean growth rate of 106 clones are reported and discussed. The variance of growth rate uas apportioned within and among ramets of a clone: the majority of the variance is environmental, with broad heritability estimated as less than or equal to .32. Analyses of gene and genotypic frequencies of polymorphic proteins revealed little differentiation with elevation, but substantial differences between the sexes. For one of three pairwise tests, the genotypes are not distributed independently of one another; linkage disequilibrium between a peroxidase locus and phosphohexose isomerase is significantly different from zero. Multiple regression revealed a positive-correlation between mean growth rate and degree of heterozygosity.
\end{abstract}

The QUAKIng aSPen, Populus tremuloides Michx., is the most widespread deciduous tree in North America (Preston, 1976). Its geographic range extends from the mountains of Mexico to northern Alaska. and from Vancouver to Nova Scotia. It is found from sea level to tree line at elevations above $3,300 \mathrm{~m}$. Perhaps one of the aspects of aspen demography that confers this adaptive flexibility is the ability to reproduce asexually. Lateral roots from one individual may send up many shoots (stems). producing a stand of trees that is actually a single individual. a clone composed of aspen ramets (Barnes. 1969).

Although aspen may form a stable climax, in most environments aspen is an early successional species (Marr. 1961). Areas burned by foresi fire or cleared by mudslide or avalanche in Colorado are often quickly covered by aspen. In some cases. the speed of colonization indicates that the area is underlain by root sys. tems of one or more clones. Indeed, clones of aspen stems may cover a few acres, and root systems may be extensive even when the aboveground parts of aspen are neither dense nor extensive. This root system and root suckering ability enables this species to be an opportunist. filling space cleared by man or nature. In most places in Colorado, aspen

\footnotetext{
'Received for publication 9 April 1979: revision accepted'3 July 1979.

We acknouledge the help of Loren Chin in the field. and Diane Bowman. Jan Logan. and Jill Gambel in the laboratory. and partial suppor from NSF grants BMS 75. 14050. DEB 76-02236. and BMD 34632.
}

succumb to shading, and are succeeded by conifers.

Quaking aspen is dioecious; the sex of a ramet may be detected by inspection of catkins in late spring or early summer, or by dissecting dormant flowering buds in the winter. Several reports document hermaphrodites or intersexes, but when these are found, the perfect catkins on a ramet are usually greatly outnumbered by single-sex catkins (Lester, 1963). In this study we encountered no problerr. in assigning a sex to a clone. Some investigators have reported sex chromosomes in aspen. (Blackburn and Harrison, 1924; Meurmann, 1925; Erlanson and Herman, 1927), but the small chromosomes of Populus make these investigations difficult and other investigators have not been able to confirm the presence of sex chromosomes (Peto, 1938: Muentzing. 1936: Smith, 1943).

The seed crop of aspen. like many forest trees, varies from year to year. but most aspen in the Front Range of Colorado produce at least some catkins every year. The seeds are tiny, buoyed by fine hairs, and may be carried considerable distances by the wind. Seeds gathered from mature catkins have high germination success in a greenhouse. but seeds dispersed in natural environments meet a stiffer test. Seeds may have high probability of success in moist environments such as the mountains of Tennessee or the forests of Michigan. but the arid environments and low relative humidity prevalent in Colorado may impose failure of the seed crop (Mart. 1961). The success of sexual reproduction in the west has been the fo 1943: Larsi rison. and

Aspen $\mathrm{cl}$ the west $\pi$ literature $\epsilon$ thousands 1975). but currently i It is certai: turies.

Sexual t genes and the record of heteroc Gibson. I! periods of cumulate types to d tion. In th principle t ally reproc of natural growth ra phism in 1 orado to $\mathrm{i}$ respect to relations : ance of grs and to te: growth ra:

MATERI from 5 ran in an area just west guarantee single clo terdigitali clones for and pragr close pro. another w In order ? only we branching and Mitic fined as a $400 \mathrm{~m}$ of separated rier (e.g. distributi 1.700-3.2 aspen.

The els with an Mitton. 1 and were the mean sex of ea. 
been the focus of debate (Moss, 1938; Ellison. 1943; Larson. 1944; Marr. 1961: Graham, Harrison. and Westell, 1963).

Aspen clones presently covering hillsides in the west may be truly ancient. Reports in the literature estimate that aspen clones may live thousands of years (Cottam. 1954: Barnes, 1975), but this estimate is difficult or perhaps currently impossible to verify quantitatively. It is certain that these clones can live for centuries.

Sexual reproduction each generation mixes genes and genotypes, and may erase some of the record of natural selection. Recent studies of heterocyclic daphnia (Hebert, Ward. and Gibson, 1972: Hebert. 1974a.b) have utilized periods of parthenogenic reproduction that accumulate fitness differentials between genotypes to detect the influence of natural selection. In this study, we have used the same principle by studying a predominantly asexually reproducing population to detect the action of natural selection. We have investigated growth rate, age, sex, and protein polymorphism in 106 clones in the Front Range of Colorado to identify genetic differentiation with respect to elevation and sex, to test for correlations among genetic loci, to partition vafiance of growth rate within and between clones, and to test for effects of heterozygosity on growth rate and growth rate variation.

MATERIALS AND METHODS-Core samples from 5 ramets of each of 106 clones were taken in an area covering approximately $500 \mathrm{sq} \mathrm{km}$ just west of Boulder, Colorado. There is no guarantee that a stand of quaking aspen is a single clone, for clones can abut or even interdigitate. Therefore, our identification of clones for sampling purposes was conservative and pragmatic. The five largest stems within close proximity (usually within $10 \mathrm{~m}$ ) of one another were chosen for leaf and core samples. In order to sample ramets from a single clone only we looked at such characteristics as branching habit, bark color, and sex (Grant and Mitton, 1979). An adjacent clone was defined as a stand of trees separated by at least $400 \mathrm{~m}$ of rerrain lacking ramets of aspen, or separated by some impassable ecological barrier (e.g, rock outcropping). The elevational distribution of the sampling area was from $1.700-3,200 \mathrm{~m}$, the approximate local limits of aspen.

The elevation of each clone was estimated with an altimeter. Growth rings (Grant and Mitton, 1979) were counted to age each ramet. and were measured to provide an estimate of the mean and variance of the growth rate. The sex of each clone was identified, and a sample of leaves was taken for electrophoretic analysis
in order to compare genotype to the morpho-

Tissue was prepared for electrophoresis in the following way. Three to six leaves from a single ramet were ground to a fine powder in a mortar and pestle under liquid nitrogen. Just as the liquid nitrogen evaporated, a $5 \%$ solution of polyvinylpyrrolidone in $.18 \mathrm{M}$ phosphate buffer $\mathrm{pH} 7.0$ was added with a pipette, and the constituents mixed to prepare a slurry. This material was not allowed to warm to room temperature: best results were obtained when the ground material partially froze the buffer. The slurry was then placed into test tubes and centrifuged for a few minutes at low speed to pack down the cellular debris. Wicks of double thickness Whatman No. 1 filter paper were used to absorb the supernatant and apply it to horizontal starch gels. The buffer system is that described in Mitton et al. (1977). Gels were stained for phosphohexose isomerase. peroxidase, and glutamate dehydrogenase by the methods in Shaw and Prasad (1970). These are the only polymorphic enzyme systems presently resolvable. Heterozygosity was scored simply as the number of loci heterozygous (03).

Heterogeneity of gene frequencies was tested with the chi-square test of Workman and Niswander (1970). The association between genotype and aspects of growth rate were tested with multiple regression, and associations among age. growth rate, elevation and sex were studied both with simple and partial correlations. This approach allows examination of dependent variable responses to independent variables with the effects of other correlated independent variables held constant.

RESULTS-Clones studied here were polymorphic for phosphohexose isomerase (PHI, 4 alleles), peroxidase (PER, 4 alleles), and glutamate dehydrogenase (GDH, 2 alleles). Our genetic interpretations of the banding patterns are supported by 1) appropriate patterns of variation (monomeric, dimeric) for each locus, and 2) genotypic frequency fits to Hardy-Weinberg expectations. The PHI and PER polymorphisms were condensed to 2 alleles by pooling rare alleles (frequency less than .10) with more commun alleles displaying similar mobilities in order to keep sample sizes large enough for statistical testing.

Complete data for age, elevation. genotype. and growth rate were taken for 98 clones. For each clone, a mean growth rate and standard deviation of growth rate was estimated, and the correlation between them was .94 ( $P<$ 
TABLE 1. Multiple regression of mean growth rate in quaking aspen

\begin{tabular}{lcl}
\hline & Coeffcients & Probability \\
\hline Mfultiple R & .606 & $P<.001$ \\
Independent variables & & \\
\hline Age & -.152 & $P<.001$ \\
Heterozygosity & 1.637 & $P<.05$ \\
Sex & 1.425 & $P>.20$ \\
Elevation & -.017 & $P<.01$ \\
\hline
\end{tabular}

$001)$. Mean growth rate was used as the dependent variable in the multiple regression analysis while age of the clone (oldest ramet). heterozygosity, sex, and elevation were employed as independent variables. Mean growth rate was found to be very highly correlated with variation in growth rate, so that all statistical relationships reported for mean growth rate hold equally well for year to year variation in growth rate as well. The multiple regression explains $37 \%$ of the variance in growth rate of clones $(P<.001$. Table 1$)$. There is no effect of sex with the effects of other independent variables held constant. Mean growth rate decreases both with age of oldest standing ramet $(P<.001)$ and elevation $(P<.01)$. The mean growth rate significantly increases with increasing helerozygosity $(P<.05)$.

Analyses of variation in the three enzymatic loci revealed different patterns. For each locus. the sample of clones was first contrasted by elevation. and then by sex. The sampling
midpoint elevation of $2,750 \mathrm{~m}$ was used to partition the clones into high and low groups. For each lixus and for each elevational group, there is good agreement between observed genotypic frequencies and those expected under assumptions of the Hardy-Weinberg Law. No differences in allelic frequencies were noted among the elevational groups (Table 2), a result contrasting strongly with the differentiation obseried between sexes. Allelic frequencies are sisnificantly different in males and females for PHI. For PER, the genotypic distributions

frequencies by elevation and by sex for three enzymatic loci in quaking aspen. TABLE 2. Comparisons of allelic frequencies by eleva unters undir Hardy-Wieinberg assumptions. $N=$ sample Numbers enclosed in parentheses are the expected nut obsenced to

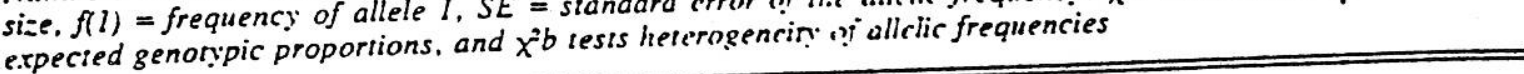

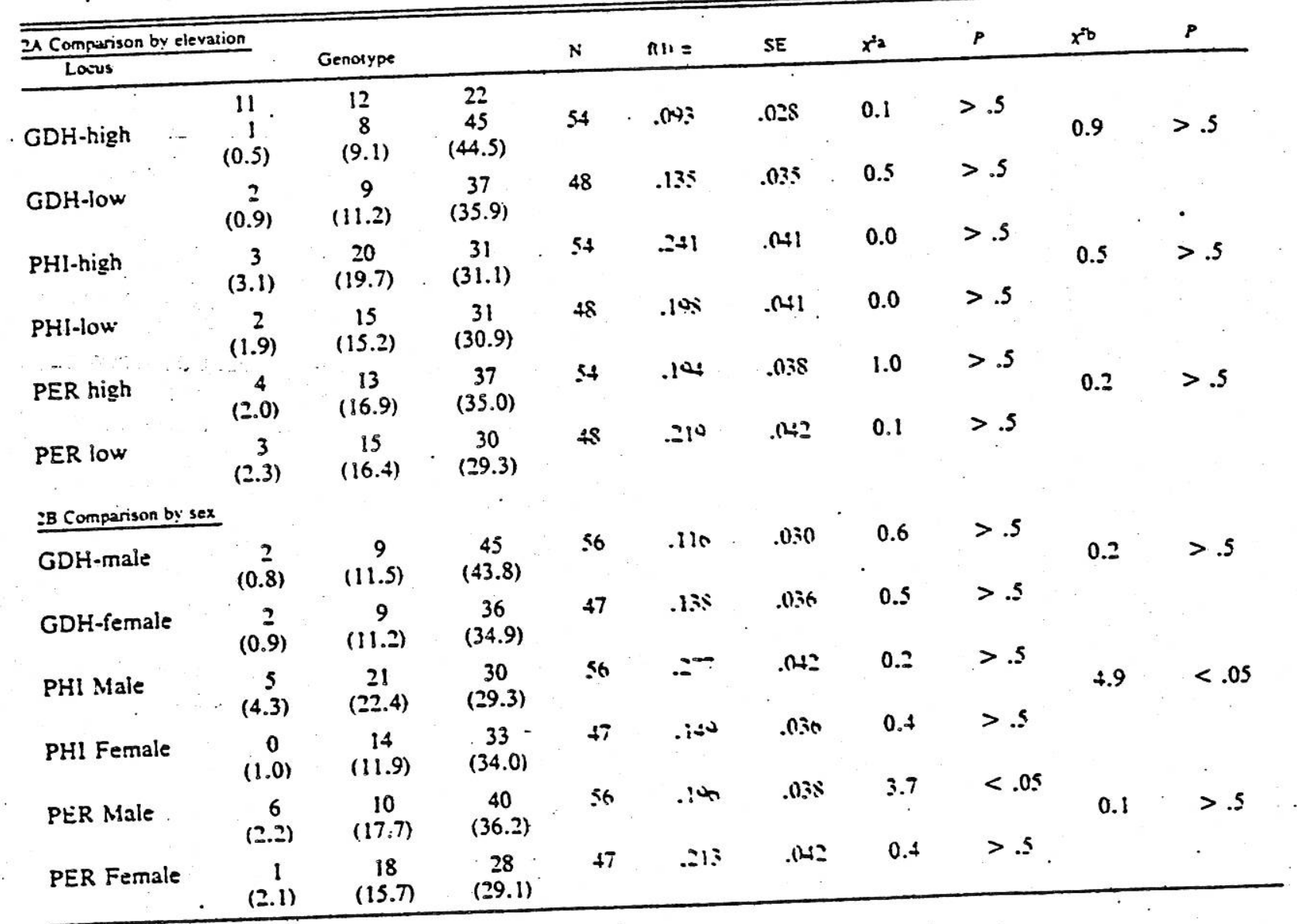


of males is significantly different than the expected. for there is a deficiency of heterozygotes. The fit of the genotypic distribution for this locus is satisfactory in females: there are a few more heterozygotes than expected. Although the allelic frequencies of PER are not different between the sexes. a row by columns test of independence of the observed genotypic frequencies indicates that genotypic frequencies are different $\left(\chi^{2}=7.2, P<.05\right)$. No differences between the sexes were noted for either allelic or genotypic frequencies at the GDH locus.

Additional evidence of non-random forces. acting upon the genetics of populations may be obtained by analyzing the joint distribution of the genotypes of different loci (Lewontin. 1974). A measure of the non-random distribution of non-homologous alleles is the parameter of linkage disequilibrium (Geiringer, 194: Thomson, 1977; Clegg, 1978). This parameter is not different from zero when calculated for the joint distributions of PER and GDH or PHI and GDH, but it is significantly different when calculated for PER and PHI. These are also the loci which are differentiated between the sexes. Although a significant value of the linkage disequilibrium parameter may indicate the action of natural selection above the level of the single gene (Lewontin, 1974), it may also be generated by the pooling of populations which differ in frequencies for those loci (Mitton, Koehn, and Prout, 1973). For these data, it is difficult to discern whether the non-random distribution of genotypes (linkage disequilibricm) is simply caused by the independent differentiation of two loci in the sexes, or whether differentiation of two loci is apparent because selection acts differently upon the joint protein genotypes in the sexes.

Individual ramets within a clone share the same genotype, and hence are identical for characters determined solely by genes. such as allozyme phenotypes. But characters that have a substantial proportion of their variance determined by environmental factors (e.g. growth rate) could differ markedly between ramets of a clone.

Our sampling design of ring width measurement allows partitioning of the variance into components (Table 3). The largest component of variance $(54 \%)$ is that within rametsgrowth rates of aspen vary considerably from year to vear for individual stems. Although the ramets of a clone are genotypically identical (barring somatic mutation), $14 \%$ of the variance in growth rates is among ramets of a clone. and is due to microsite differences in soil, sunlight, water availability, etc.: $33 \%$ of the variance in growth rates is among clones.
TABLE 3. Apportiomment of variance of yrowth rate within and among ramers of inule and female clones of quaking aspen. Populus iremiulvides

\begin{tabular}{lcc}
\hline \hline \multicolumn{1}{c}{ Variance compunens } & Variance & Percens \\
\hline Between years. within ramets. & & \\
within clones. within sexes & $\$ 3.56$ & 53.85 \\
Between ramets. Within clones. & & \\
within sexes & 10.94 & 13.52 \\
Between clones, within sexes & 26.52 & 32.78 \\
Between sexes & -.13 & -.16 \\
\hline
\end{tabular}

of the same sex. The proportion of the variance among sexes is approximately zero.

A rough estimate of heritability of variance of growth rate may be generated from these data. Both the variation within ramets across years and the variation among ramets of a clone are strictly environmental. Variation among clones has two components; they differ genetically and occur in a diverse array of environments. Variation among the sexes is. once again. both genetic and environmental. but this component of variance approaches zero. and may be ignored for this rough estimate. Interactions may well occur between genetic and environmental portions of these variance components. but we cannot estimate them from these data, so we must assume. for these calculations, that they approach zero. If the strictly environmental components of variance are subtracted from the total phenotypic variance, we are left with the among clones within sexes component, which should have both genetic and environmental portions. If we utilize this component to estimate an upper bound to the broad sense heritability of growth rate $\left(h^{2}=\right.$ variance among clones/total phenotypic variance), the upper bound is $32.6 \%$.

A generalization commonly held concerning broad sense heritability is that characters with a strong influence on fitness have low levels of heritability-an optimum phenotype is chosen by artificial or natural selection, and the majority of genetic variation influencing that character has been eliminated (Falconer. 1960). This generalization is compatible with our data, which suggest an upper bound of heritability of variance of growth rate to be about $33 \%$. It is our belief that characteristics of growth are important in the determination of fitness.

Cores from several ramets. of each clone provide minimum estimates of clone age only. but such ages do have substantial biological significance indicating, for example, how recently fires and avalanches have perturbed the forest. The age distribution for clones is given in Fig. 1, and-correlations between age and 
and to ermine nes re-

incy of inconone 15. land on y been ar there tion reind posseemed overlap - of this th a dised with of Rohlf :ollected of each enzyme new that le stand. can proof clones , the ady further are only ex of the sisely the mets proa may be (Fig. 2). occupied ied solely 3ark color se clones, Eerrale raale ramets :ts appear or female. he second

e. Euch claso. which it was

$=$

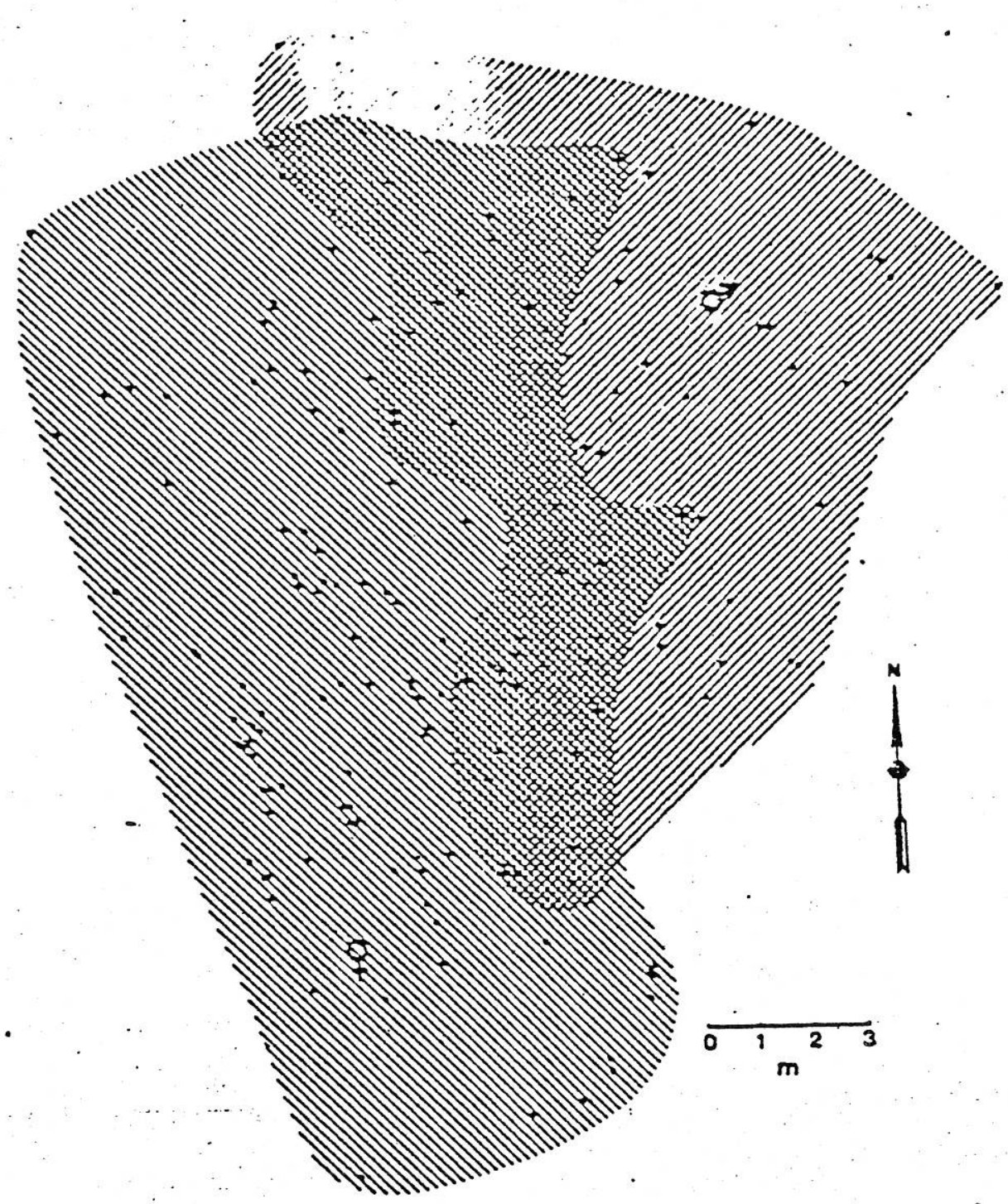

2. Interdigitation of clones of aspen. The genutype of each ramet (0) has been identifiect for three protein loci. See text for further explanation.

allele of peroxidase, but the female is hetervzygous for the remaining loci, and the male is homozygous for all three of these markers.

Clones of aspen that differ genetically and overlap in space provide a natural experiment to test for genetic influences upon growth rate. To describe growth rates. cores were taken from approximately 20 ramets of each clune. and ring widths were measured to estimate the mean and variance of growth rates. The means were not different, but the variances were. The more heterozygous female clone had the greater variance $(P<.05)$ in growth rate.

Discussion-The results of this study indicate a significant positive relationship between heterozygosity and mean gruwth rate. We know from biochemical studies that heterozygous individuals may have greater phys- iological versatility than their homozygous counterparts (e.g.. Hochachka and Somero. 1973; Fincham, 1972; Johnson, 1976), but we are not yet in a position to specify the mechanistic causes of the observed higher growth rate of heterozygotes. Our data do suggest a role of the test loci. or perhaps other closely linked loci. in a trait (differential growth rate) which undoubtedly affects fitness. We believe the effect is probably from the observed loci since it is not sufficient to postulate that loci closely linked to the ones observed be involved in the growth rate. There would also have to be linkage disequilibrium between the enzymatic loci and the linked loci to produce the observed result. Linkage disequilibrium is certainly found in natural populations. but it is rarely of sufficient magnitude to produce the effect considered here (Clegg, 1978). 
The results of the multiple regression indicate that the effect of a single additional heterozygous locus is detectable. There are precedents for this observation (Mitton. 1978; Eanes. 1978; Singh and Zouros, 1978), but it is nevertheless remarkable that a significant relationship between heterozygosity and growth rate could be detected by utilizing only three loci, notwithstanding theoretical arguments (Kimura and Ohta, 1971) and some empirical data (Fuerst, Chakraborty. and Nei. 1977) that suggest that protein polymorphisms have little or no impact upon fitness. It is difficult to image how heterozygosity at a single locus can influence the phenotype of an organism polymorphic for hundreds or thousands of loci (Lewontin, 1974). However. since we did detect such an effect, it is probable that natural selection could also.

In this study. the measure of growth rate has been based upon the width of annual growth rings of several ramets per clone. This measure is easily obtained. and is valuable as a measure of adaptation or vigor, but annual rings do not indicate the true age of the clone. nor do they tell anything about the relative apportionment of energy to asexual reproduction. sexual reproduction, or growth of the root stock. It may well be that in terms of understanding the long term viability of a clone, energy channeled into sexual reproduction or invested in the root system may be more informative than age or growth rate in standing ramets. Growth rates measured from standing ramets indicate both genotypic and environmental effects. and. at least partially, reffect the degree to which a clone is adapted to its specific environment.

We observed an interesting contrast between the relationships among age. diameter. and ring width in aspen versus ponderosa pine. Within a stand of ponderosa pine. diameter is a good predictor of age, which could vary from a few to several hundred years. In contrast. the distribution of age of ramets of aspen has relatively low variance in our sample (Fig. 1). and age could not be accurately predicted from diameter (Table 4). The life expectancy of an aspen ramet in the Colorado Front Range is $50-70$ years at best. The ages of the oldest standing ramets may simply refiect pressure from herbivores, diseases. competition from conifers. or stress imposed by the physical components of the environment. Ring width generally decreases with age of a tree (Fritts. 1976). yet there is a positive partial correlation between diameter and ring width in this sample (r $-.221 . P<.001)$. Within a ramet. ring width decreases with age. but perhaps some trees simply grow much faster than others. but have similar longevities in the Front Range environment. The correlation between these variables may be a consequence of the dynam. ics of an early successional species;

There are certainly some problems associated with working with clones in the field. In this species, it is difficult to determine the extent of a clone (but see Barnes, 1969), for they may overlap and the root system could conceivably extend far beyond presence of ramets. We were able to document overlap of clones here (Fig. 2), but we have not by any means delimited the extent of all clones.

To balance the disadvantages of working with clones, there are some distinct advantages. Ramets provide replicates of an individual and regeneration by asexual reproduction changes a long-lived perennial to a perennial with exceedingly long generation times. Intensities of natural selection that might not be detected over several decades may be immediately apparent if natural selection is allowed to work for several centuries or millenia. The time spans involved here can only be guessed at. but geographic variation in sex ratio (Grant and Mitton, 1979) and differentiation of allelic frequencies between the sexes (Table 2) is now apparent.

Our finding that allelic frequencies were independent of elevation stands in marked contrast to previous studies of other Front Range taxa (Grant and Mitton, 1977: Mitton et al., 1977). The elevational transect studied encompasses a wide range of environmental conditions and we expected to find corresponding genetic differentiation.

The contrasting finding (significant allelic and genotypic differentiation between the sexes) is consistent with data which indicate. that proportions of male and female clones vary with elevation, probably as a result of differential mortality (Grant and Mitton. 1979). Whatever the mechanisms. natural selection is apparently influencing the sexes differentially.

\section{LITERATURE CITED}

BarNes. B. V. 1966. The clonal growth habit of American aspens. Ecology 47: 439-447.

. 1969. Natural variation and delineation of clones of Populus tremuloides and $P$. grandideniaia in norhern lower Michigan. Silvae Genet. 18: 130-142. -1975. Phenotypic variation of trembling aspen of western North America. For. Sci. 21: 319-328.

BlaCKBURN. K. B.. AND J. W. H. HARRISOX. 1924. A preliminary account of the chromosomes and chro. mosome behavior in Salicaceae. Ann. Bot. 38: 361378.

CLEGG. M. C. 1978. Dynamics of correlated genetic systems. II. Simulation studies of chromosomal segments under selection. Theor. Pop. Biol. 13: 1-23.

CotTaM. W. P. 1954. Prevernal leafing of aspen in the 
Utah Muuntains. J. Arnold. Arbor. Harv. Univ. 35: 239-248.

EA.ves. W. F. 1978. Morphological variance and enzyme hecerozygosity in the Monarch buttertly. Nature 276: 263-264.

ELLISON. L. 1943. A natural seedling of westem aspen. J. For. 41: 767-768.

Erlanson. E. W.. ANd F. J. Herman: 1927. The murphology and cytology of pertect flowers in Populus tremuloides Michx. Pap. Afich. Acad. Sci. 8: 97-110.

FALCONER. D. S. 1960 . Introduction to quantitative genetics. Ronaid Press. New York

Fivchas, J. R. S. 1972. Heterozygous advantage as a likely general basis for enzyme polymurphisms. Heredity 28: $387-391$.

FITTS. H. C. 1976. Tree rings and climate. Academic Press. New York.

. NE1. 1977. Statistical studies on protein polymurphism in natural populations. 1. Distribution of single locus hetero zygosity. Genetics $86: 455-483$.

Geiringer, H. 1944. On the probability theory of linkage in Mendelian heredity. Ann. Math. Stat. 15: 25-50.

GrahaM. S. A.. R. P. HARRISON. AND C. E. VESTELL. 1963. Aspens. Univ. of Michigan Press. Ann Arbor. 1963. Aspens. Und J. B. MitTON. 1979. Elevational

Grant. M. C.. AND J. B. Mitron. gradients in adult sex ratios and sexualdifterentiation tremuloides in vegetative growth rates, of

Michx. Evolution 33: 914

- AND - 1977. Genetic differentiationalo subalpine fir growth forms of Engelmann spruce 259-263. at tree line. Arct. Alp. Res. 9:

HaNCOCK. J. F.. JR.. AND R. E. WILson. selection in Erigeron annulus 103: 122-125. sion. Bull. Torrey Bot. Club lobility in natural popu-

HeberT. P. 1974a. Enzyme variability Genotypic frequencies lations of Daphnia magna. 11. Getics 77: 323-334. in permanent populations. Genetics 77 in 1974b. Enzyme variability in natural pupulas in inof Daphniu magna. Henetics 77: 335-341. termittent populations. 1972 Natural selection for

- AND R. D. WARD. 1972. Nathenogenetic Daphnia enzyme variants amos. 19: 173-176.

mogna. G Ptrategies

HochachK.t. P.. AND G. N. So. B. Saunders Co.. Philaof biochemi

Jornson. G. B. 1976. Genetic polymorphism and enzyme function. In F. J. Ayala [ed.]. Molecular evolution. Sinauer Assoc. Stamford. Connecticut.

KIMURA. M.. AND T. OHTA. 1971. Protein polymorphism as a phase of molecular evolution. Nature 229: 467469. asov. G. C. 1944. More un seedlings of westem aspen. J. For. 42: 452.

Lester. D. T. 1963. Variation in sex expression in POPulus tremuloides Michx. Silvae Genet. 12: 1+1-180.

Ewovis. R. C. 1974. The genetic basis of evolutionary thange. Columbia University Press. New York.

R. WV. 1961. Ecosystems of the east slupe of the Front Range in Colurado. Univ. of Colo. Stud. Ser. Biol. 8: $1-134$.

MELRMAN. O. 1925. The chromosome behavior of some Jivecious plants and their relatives with special reference to the sex chromusomes. Soc. Sci. Fennica. Commentations Biol. 2: 1-104.

Coss. E. H. 1938. Longevity of seed and establishment of seedlings in species of Populus. Bot. Gaz. 49: 529ist2.

1970v. B. 1978. Relationship between heterozygusity for enzyme loci and variation of morpholugical tharacters in natural pupulations. Nature 273: $661-662$. - R. K. KOEHN. AND T. Prout. 1973. Population genetics of marine pelecypods. III. Epistasis between functionally related isoenzymes of Mytilus edulis. Genetics 73: $497-196$.

-. Y. B. LINHART. J. L. HAMRICK, AND S. S. BECKMAN. 1977. Observations on the genetic structure and mating system of punderosa pine in the Coluradio Front Range. Theor. Appl. Genet. 51: 5-13.

iuentzing. A. 1936. The chromusomes of a giant Populus tremula. Hereditas 21: 383-393.

PETO. F. H. 1938. Cytology of puplar species and natural hybrids. Can. J. Res. 16: $145-155$.

. 1976. North American Trees. lowa State Univ. Press. Ames.

ARCHIE, 1978 . Least squares mapping using interpoint distances. Ecology 59: 126 132.

Priv. PraStD. 1970. Starch gel electrophuresis of enzymes-a compilation of recipes. Biochem. Genet. 4: 297-320.

St:GH. S. M., AND E. Zouros. 1978. Genetic variation associated with growth rate in the American oyster (Crassostrea virginica). Evolution 32: 342-353.

E. C. 1943. A study of cytology-and speciation in the genus Populus L.J. Amold Arbor. Harv. Univ. 24: 275-305.

Thousor G. 1977. The effect of a selested locus on linked neutral loci. Genetics 85: 753-788.

VASEK. F. C. 1966. The distribution and taxonomy of three western junipers. Brittonia 18: 350-372.

WORK lation studies on Southwestern Indian tribes. II. Local differentiation in the Papago. Am. S. Hum. Genet. 22: 249 . tion of slunes ndidentuses in - $18: 130-1+2$. bling aspen of 319-323. son. 1924. A mes and shro Bot. 38: 361ted genetic sysjumal segments $: 1-23$. of aspen in the 